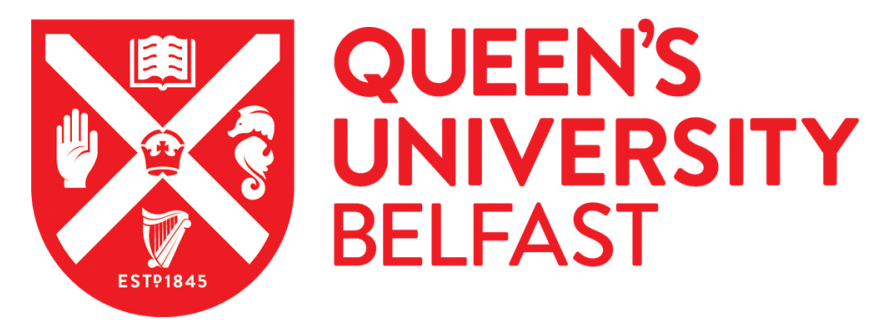

\title{
Drug stability and product performance characteristics of a dapivirine- releasing vaginal ring under simulated real-world conditions
}

Murphy, D. J., McCoy, C. F., Boyd, P., Derrick, T., Spence, P., Devlin, B., \& Malcolm, R. K. (2019). Drug stability and product performance characteristics of a dapivirine-releasing vaginal ring under simulated real-world conditions. International Journal of Pharmaceutics, 565, 351-357. https://doi.org/10.1016/j.ijpharm.2019.05.027

Published in:

International Journal of Pharmaceutics

\section{Document Version:}

Peer reviewed version

Queen's University Belfast - Research Portal:

Link to publication record in Queen's University Belfast Research Portal

\section{Publisher rights}

Copyright 2019 Elsevier.

This manuscript is distributed under a Creative Commons Attribution-NonCommercial-NoDerivs License

(https://creativecommons.org/licenses/by-nc-nd/4.0/), which permits distribution and reproduction for non-commercial purposes, provided the author and source are cited.

\section{General rights}

Copyright for the publications made accessible via the Queen's University Belfast Research Portal is retained by the author(s) and / or other copyright owners and it is a condition of accessing these publications that users recognise and abide by the legal requirements associated with these rights.

Take down policy

The Research Portal is Queen's institutional repository that provides access to Queen's research output. Every effort has been made to ensure that content in the Research Portal does not infringe any person's rights, or applicable UK laws. If you discover content in the Research Portal that you believe breaches copyright or violates any law, please contact openaccess@qub.ac.uk. 

dapivirine-releasing vaginal ring under simulated real-world

5 Diarmaid J. Murphy ${ }^{\text {a\# }}$, Clare F. McCoy ${ }^{\text {a\# }}$, Peter Boyd ${ }^{\mathrm{a}}$, Tiffany Derrick ${ }^{\mathrm{b}}$, Patrick 


\section{Abstract}

20 In two recent Phase III clinical trials, use of a $25 \mathrm{mg}$ dapivirine vaginal ring significantly reduced

21 HIV acquisition rates. Post hoc analysis from one of the trials indicated higher rates of protection

22 among women over the age of 21 years when compared to younger women, most likely due to

23 reduced adherence in the latter group. There is currently no information available on how release

24 of dapivirine from the ring is affected by either its intermittent removal from the vagina or

25 women's cleaning of the ring before re-insertion. Here, in vitro drug stability and product

26 performance characteristics of the dapivirine ring were assessed under simulated conditions of

27 real-world use. The impact of systematic deviations from the 28-day continuous use protocol

28 upon in vitro release performance, was investigated. Also, the effect of ring exposure to a range

29 of common household chemicals - including bath salts, bleach, detergent and personal lubricants

30 - was examined through measurement of dapivirine content and stability. Dapivirine in vitro

31 release under intermittent schedules was similar to that obtained under the normal continuous

32 schedule ignoring the periods of interruption. Ring exposure to various household chemicals had

33 no discernible impact on dapivirine assay value, degradation or stability.

35 Keywords: HIV microbicide; Antiretroviral; Silicone elastomer vaginal ring; Intermittent use 36 protocol

38 Abbreviations: DPV - dapivirine, IPA - isopropanol, IPA/water - 1:1 mixture of isopropanol 39 and water, IPM - International Partnership for Microbicides, MTN - microbicides trial network, 40 NOR - 19-norethindrone, RT - room temperature, SVF - simulated vaginal fluid, SVF/Tween - 
41 simulated vaginal fluid with $0.2 \%$ Tween $80, \mathrm{rpm}$ - revolutions per minute, RRT - relative

42 retention time, TFA - trifluoroacetic acid. 


\section{1. Introduction}

44 Antiretroviral-releasing vaginal rings are a promising female-controlled biomedical strategy for 45 reducing rates of HIV acquisition (Malcolm et al., 2016, 2014; Spence et al., 2015; Thurman et

46 al., 2013). Among the advantages offered by this technology are the ability for the user to easily

47 insert/remove rings without the need for medical intervention and the ability to offer long-acting 48 administration of the antiretroviral agent(s) over many weeks or months (Boyd et al., 2016; Clark 49 et al., 2014; Malcolm et al., 2016).

51 The dapivirine (DPV) releasing vaginal ring (Ring-004) is the most clinically advanced 52 microbicide ring formulation (Malcolm et al., 2016). This matrix-type design comprises $25 \mathrm{mg}$ 53 micronised DPV homogeneously dispersed throughout a platinum-catalysed silicone elastomer 54 ring. The ring has an outer diameter of $56 \mathrm{~mm}$ and an internal diameter of $7.7 \mathrm{~mm}$. In 2016, the 55 results from two Phase III clinical trials were reported in which the DPV ring was tested for 56 prevention of HIV-1 acquisition. A 27\% and 31\% reduction in seroconversions was measured in 57 the Aspire Study (MTN-020) and The Ring Study (IPM 027), respectively, compared to a non58 medicated control ring (Baeten et al., 2016; Nel et al., 2016b). In the ASPIRE study, the level of 59 protection afforded by the ring correlated strongly with participant age. For women aged 25 or 60 over the incidence reduction was $61 \%$. However, among women aged under 25, the protective 61 efficacy was just 10\%. In a post hoc exploratory analysis of age-categorized subgroups, the lack

62 of protection among younger women was correlated with lower adherence (Baeten et al., 2016).

63 A similar, though not statistically significant, reduction in efficacy was observed in The Ring 64 Study $-37 \%$ vs. 15\% for women over and under 21, respectively (Nel et al., 2016b). These 65 correlations between adherence and efficacy mirror results in previous microbicide clinical 
66 studies involving tenofovir tablets and vaginal gels in which no protective effect was observed

67 (Marrazzo et al., 2015; Van Damme et al., 2012). Interestingly, subsequent re-analysis of data

68 from the VOICE study showed that a protective effect with a vaginally administered tenofovir

69 gel could be detected among adherent participants (Dai et al., 2016). Although adherence to

70 study medication was deemed to be a major contributing factor to the lack of effect observed, it

71 was not the only factor, particularly for tenofovir-containing products (Kashuba et al., 2015;

72 McKinnon et al., 2018). Interim data from two open-label extension studies of the $25 \mathrm{mg}$ DPV

73 ring - HOPE (MTN-025) and DREAM (IPM 032) - indicate that with a higher adherence rate,

74 the level of protection afforded by the ring rises to approximately 50\% (Baeten et al., 2018; Nel

75 et al., 2018).

76

77 The contraceptive field has a long history of assessing user acceptability and adherence, and the

78 user issues previously reported for contraceptive vaginal rings are likely to be encountered again

79 with microbicide rings (Dieben et al., 2002; Novák et al., 2003; Stifani et al., 2018; Woodsong

80 and Holt, 2015). Studies examining women's perceptions and motivations for ring use and

81 reasons for ring removal have been reported (MacQueen et al., 2014; Montgomery et al., 2012;

82 Nel et al., 2016a; Van Der Straten et al., 2012). Many factors are known to impact adherence to

83 microbicide rings, including ring removal for menses, sex or washing and the feelings and

84 opinions of sexual partners (Montgomery et al., 2017). In clinical studies, increased familiarity

85 and experience with vaginal ring use among study participants, coupled with counselling and

86 support from clinical staff, can significantly increase positive clinical outcomes (Montgomery et

87 al., 2017). 
89 There are a number of ways in which women's use of a ring may deviate from so-called 'perfect

90 use'. For example, the ring may be removed or be expelled periodically. Consequently, the

91 length of time the ring is located outside of the vagina will impact the concentrations of

92 dapivirine in the vaginal fluid and hence product efficacy after removal. The performance of the

93 ring under conditions of imperfect use is unknown. As well as not wearing the ring for the

94 intended duration, it may also be washed or exposed to other cleaning fluids in the course of

95 normal use. Exposure of rings to other household or personal hygiene products could potentially

96 affect their in vivo performance. In studies examining acceptability of a tenofovir disoproxil

97 fumarate ring among women from New York, users were concerned about the ring potentially

98 absorbing blood and getting dirty if it remained inserted during menses (Watnick et al., 2018). In

99 a previous study, between 4 and $18 \%$ of women reported removing the ring either during menses

100 or for periodic cleaning (Montgomery et al., 2012). Application of a variety of different

101 substances to the vagina for general health, cleaning or sexual function has also been reported in

102 different populations (Gafos et al., 2010; Low et al., 2011; Martin Hilber et al., 2010; Pines et al.,

103 2018). Further, previous clinical studies have observed ring discolouration following use (Spence

104 et al., 2016). To the best of our knowledge, the impact of ring exposure to wash products or other

105 vaginally-administered products has not been reported.

106

107 Here, we have examined: (i) the impact of periodic removal and storage of the dapivirine-

108 releasing vaginal ring (Ring-004) during in vitro release testing; (ii) ring performance following

109 exposure to various products common in Sub-Saharn African households, including two bath

110 salts, an oral pill containing natural products that was suspected to cause ring discolouration,

111 three vaginal lubricants, a liquid household detergent and a household bleach; and (iii) the 
112 impact of exposure on the DPV content of the ring and the potential for undesirable breakdown 113 product formation.

\section{2. Materials and methods}

\section{$116 \quad 2.1$ Materials}

117 Matrix-type, silicone elastomer vaginal rings nominally containing $25 \mathrm{mg}$ dapivirine (Ring-004, 118 mean measured DPV content per ring $24.4 \pm 0.15 \mathrm{mg}$ ) were manufactured at QPharma (Malmö, 119 Sweden) and supplied by International Partnership for Microbicides (IPM). Potassium 120 dihydrogen orthophosphate, potassium hydroxide, trifluoroacetic acid (TFA) and urea (AnalaR, 121 analytical reagent grade) were purchased from VWR International Ltd. (Dublin, Ireland). 19-

122 Norethindrone (NOR) was purchased from LGM Pharma (Nashville, USA). HPLC-grade 2123 propanol (IPA), methanol, acetone, acetonitrile, phosphoric acid ( $85 \% \mathrm{w} / \mathrm{w}$ in water), Tween 80 , 124 sodium chloride, calcium hydroxide, bovine serum albumin, lactic acid, acetic acid and glucose 125 were all purchased from Sigma-Aldrich (Gillingham, UK). A Millipore Direct-Q 3 UV Ultrapure 126 Water System (Watford, UK) was used to obtain HPLC-grade water. Simulated vaginal fluid 127 (SVF), $\mathrm{pH} 4.2$ with $0.2 \% \mathrm{w} / \mathrm{v}$ Tween 80 (SVF/Tween) release media, was prepared according to 128 a previously described method followed by the addition of the Tween 80 component (Owen and 129 Katz, 1999). Revive Bath Salts, Sols Bath Salts, and DeWitt's K\&B Pills were provided by IPM 130 (Table 1). The DeWitt's K\&B Pills (a traditional African product) were reported to have been 131 taken by some participants in Phase III clinical trials; the blue colour of the pills matches that 132 observed for a small number of rings following clinical use (IPM, unpublished data) and is 133 known to cause blue/green urine discolouration. The vaginal lubricants Replens MD, SuperSlik 134 and Sliquid were purchased from Amazon.co.uk (Table 1). The detergent (Fairy Liquid, a 
136 from a local supermarket (Table 1).

138 Table 1. Vaginal lubricants, detergent, bleach and bath salts products tested

Product name

A Super Slik water-based lubricant

B Replens MD Vaginal Moisturiser

C Sliquid Silver Luxury Silicone Lubricant

D Fairy Liquid washing up liquid

E Domestos bleach

F Revive Bath Salts

G Sols Bath Salt (Itshe Abelungu)

H DeWitt's K\&B (Kidney and Baldder) Pills
Ingredients

water, glycerine BP, monopropylene glycol USP, hydroxyethyl cellulose, sodium methylparaben, sodium ethylparaben, sodium propylparaben

purified water Ph.Eur, glycerin, mineral oil, polycarbophil, carbomer homopolymer Type B, hydrogenated palm oil glyceride, sorbic acid, sodium hydroxide

cyclopentasiloxane, dimethicone, dimethiconol

water, sodium laureth sulphate, alcohol denatured, lauramine oxide, C9-11 pareth-8, sodium chloride, 1,3-

cyclohexanedimethanamine, polypropylene glycols, dimethyl aminoethyl methacrylate/hydroxyproplyacrylate copolymer citrate, parfum, geraniol, limonene, colourant

sodium hypochlorite, C12-C18 alkyl dimethylamine oxide cationic surfactants, non-ionic surfactants, sodium hydroxide, soap, perfume

sodium sesquicarbonate, sodium bicarbonate, sodium lauryl sulphate, fragrance, propylene glycol, panax ginseng seed oil, eucalyptus globulus leaf oil, amycl cinnamal, citral, citronellol, coumarin, geraniol, butylphenyl methylpropional, limonene, linalool, CI 42090

not available; pink coloured viscous liquids and salts (Cocks and Moller, 2002)

dry Buchu (Agathosma) extract, Bearberry extract, magnesium stearate, paraffin wax, talc

\section{$141 \quad 2.2$ In vitro release testing of rings}

142 In vitro release testing of the $25 \mathrm{mg}$ DPV rings was performed according to the schedule and

143 conditions summarised in Table 2. On Day 0, rings were weighed and placed into individually 
144 labelled $250 \mathrm{~mL}$ glass flasks containing $200 \mathrm{~mL}$ of either 1:1 mixture of IPA and water 145 (IPA/water) or SVF/Tween. Flasks were sealed and placed in a temperature-controlled orbital 146 shaking incubator $\left(37^{\circ} \mathrm{C}, 60 \mathrm{rpm}, 25 \mathrm{~mm}\right.$ orbital throw). On Day 1, each flask was removed from

147 the incubator after $24 \mathrm{~h} \pm 15 \mathrm{~min}$, gently shaken for $10 \mathrm{~s}$, and then a $1-2 \mathrm{~mL}$ sample of the 148 release medium taken for HPLC analysis. Rings scheduled to be placed on storage were removed 149 from the release medium, rinsed with distilled water and blotted dry, before being placed in 150 individually labelled polyethylene sample bags and stored in the dark at either ambient 151 temperature or $4^{\circ} \mathrm{C}$. Otherwise, the release medium was replaced with $100 \mathrm{~mL}$ of fresh medium 152 before the flasks were returned to the incubator. Sampling and complete replacement of the 153 release medium continued daily (except for weekends) for those rings scheduled to be on release.

154 Each Friday, the volume of release medium used was increased to $200 \mathrm{~mL}$, and no sampling or 155 release medium replacement occurred during weekends. 
156 Table 2. Summary of the test groups, schedule and conditions for DPV ring in vitro release testing, mean residual content values, mean

157 cumulative in vitro release and total calculated DPV recovery values ( $\mathrm{n}=3$ rings per study group). Ring codes beginning with ' $\mathrm{P}$ ' and ' $\mathrm{S}$ ' refer to

158 rings released into IPA/water and $\underline{\mathrm{S} V F / T w e e n}$ media, respectively.

159

\begin{tabular}{|c|c|c|c|c|c|c|c|}
\hline Ring code & Testing days & Release medium* & $\begin{array}{l}\text { Storage } \\
\text { temperature } \# \square\end{array}$ & $\begin{array}{l}\text { Mean residual } \\
\text { content (mg) }\end{array}$ & $\begin{array}{l}\text { Mean cumulative } \\
\text { release (mg) }\end{array}$ & $\begin{array}{l}\text { Mean total DPV } \\
\text { recovery }(\mathrm{mg})\end{array}$ & $\%$ Recovery \\
\hline Control & - & - & - & $24.30 \pm 0.41$ & - & - & 99.6 \\
\hline $\mathrm{PC}$ & $1-28$ & IPA/water & - & $11.21 \pm 0.18$ & $12.84 \pm 0.30$ & 24.05 & 98.6 \\
\hline $\mathrm{P} 1$ & 1 and 28 & IPA/water & $\mathrm{RT}$ & $21.07 \pm 0.19$ & $3.40 \pm 0.02$ & 24.47 & 100.3 \\
\hline P2 & 1 and 28 & IPA/water & $4^{\circ} \mathrm{C}$ & $20.79 \pm 0.29$ & $3.38 \pm 0.02$ & 24.17 & 99.1 \\
\hline P3 & $1,8,15,22 \& 29$ & IPA/water & $\mathrm{RT}$ & $18.89 \pm 0.26$ & $5.53 \pm 0.03$ & 24.42 & 100.1 \\
\hline P4 & $1,8,15,22 \& 29$ & IPA/water & $4^{\circ} \mathrm{C}$ & $19.02 \pm 0.27$ & $5.57 \pm 0.01$ & 24.59 & 100.8 \\
\hline P5 & $1-7$ and $21-28$ & IPA/water & $\mathrm{RT}$ & $14.89 \pm 0.40$ & $9.40 \pm 0.02$ & 24.28 & 99.5 \\
\hline P6 & $1-7$ and $21-28$ & IPA/water & $4^{\circ} \mathrm{C}$ & $14.88 \pm 0.15$ & $9.39 \pm 0.04$ & 24.27 & 99.5 \\
\hline $\mathrm{SC}$ & $1-28$ & SVF/Tween & - & $19.23 \pm 0.28$ & $4.89 \pm 0.10$ & 24.12 & 98.8 \\
\hline S1 & 1 and 28 & SVF/Tween & $\mathrm{RT}$ & $23.73 \pm 0.33$ & $0.72 \pm 0.03$ & 24.45 & 100.2 \\
\hline S2 & 1 and 28 & SVF/Tween & $4^{\circ} \mathrm{C}$ & $24.01 \pm 0.34$ & $0.74 \pm 0.03$ & 24.76 & 101.5 \\
\hline $\mathrm{S} 3$ & $1,8,15,22 \& 29$ & SVF/Tween & $\mathrm{RT}$ & $23.21 \pm 0.60$ & $1.62 \pm 0.02$ & 24.83 & 101.8 \\
\hline S4 & $1,8,15,22 \& 29$ & SVF/Tween & $4^{\circ} \mathrm{C}$ & $22.62 \pm 0.33$ & $1.57 \pm 0.06$ & 24.19 & 99.2 \\
\hline S5 & $1-7$ and $21-28$ & SVF/Tween & RT & $21.38 \pm 0.46$ & $3.08 \pm 0.11$ & 24.26 & 100.3 \\
\hline S6 & $1-7$ and $21-28$ & SVF/Tween & $4^{\circ} \mathrm{C}$ & $21.06 \pm 0.19$ & $3.17 \pm 0.08$ & 24.23 & 99.3 \\
\hline
\end{tabular}

160

$161{ }^{*}$ IPA/water - 1:1 mixture of isopropanol and water; SVF/Tween - simulated vaginal fluid with $0.2 \% \mathrm{w} / \mathrm{v}$ Tween 80

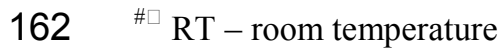




\subsection{Ring exposure to bath salts, detergent, bleach and personal lubricants}

164 DPV rings were exposed to a range of household products (two different bath salts, a pill

165 containing natural extracts, a household liquid detergent and a household bleach) and three

166 different personal lubricants to assess the impact on drug content and stability (Table 1). The

167 range of wash solutions included bath salt brands widely available in South Africa as well as

168 commonly used detergent and bleach products from the UK. Exposure conditions (wash solution,

169 temperature, time) for each test are outlined in Table 3. The personal lubricants were selected to

170 include aqueous-based, mineral oil-based, and silicone oil-based products. Exposure durations

171 (1-4 h), temperatures $\left(37-50^{\circ} \mathrm{C}\right)$ and product test volumes were selected to mimic real world

172 conditions. Untreated rings, rings exposed to SVF/Tween only, and rings exposed to water only

173 were used as study controls. Diluted solutions of each personal lubricant product (to mimic

174 product dilution with vaginal fluid) were prepared by mixing $15 \mathrm{~g}$ of the lubricant with $5 \mathrm{~g}$ of

$175 \mathrm{SVF} /$ Tween prior to ring addition. Detergent and bleach products $(4 \mathrm{~g})$ were diluted in water (16

176 g). Bath salt solutions were prepared by addition of $1 \mathrm{~g}$ bath salt to $100 \mathrm{~mL}$ water with stirring

177 for 5 min. Revive Bath Salts and and DeWitt's K\&B Pills were not fully dissolved after mixing

178 at either ambient temperature or $40^{\circ} \mathrm{C}$ for $30 \mathrm{~min}$, but were still used for testing. $20 \mathrm{~mL}$ or $20 \mathrm{~g}$ of

179 each product solution/dispersion was used to fully cover the ring in the flask. 
Table 3. Experimental conditions and mean DPV recovery values and percentages for rings exposed to bath salts, detergent, bleach and personal lubricant test solutions. $\mathrm{n}=3$ rings per test solution. Rings were exposed to all test solutions under controlled agitation $(60 \mathrm{rpm}$, except for the 'no wash solution' control).

\begin{tabular}{lllll}
\hline Test solutions & $\begin{array}{l}\text { Exposure } \\
\text { time }(\mathrm{h})\end{array}$ & $\begin{array}{l}\text { Exposure temperature } \\
\left({ }^{\circ} \mathrm{C}\right)\end{array}$ & $\begin{array}{l}\text { Mean DPV recovered (mg) } \pm \\
\text { SD }\end{array}$ & $\begin{array}{l}\text { Mean \% recovery } \\
\pm \mathrm{SD}\end{array}$ \\
\hline No wash solution & - & - & $24.44 \pm 0.41$ & $100.2 \pm 1.7$ \\
SVF/Tween & 4 & 37 & $24.34 \pm 0.37$ & $24.17 \pm 0.31$ \\
Super Slik Lubricant + SVF/Tween (3:1) & 4 & 37 & $24.18 \pm 0.20$ & $99.8 \pm 1.5$ \\
Replens MD + SVF/Tween (3:1) & 4 & 37 & $24.35 \pm 0.17$ & $99.1 \pm 1.3$ \\
Sliquid Silver Luxury Silicone Lubricant + SVF/Tween (3:1) & 4 & 37 & $25.02 \pm 0.27$ & $99.8 \pm 0.7$ \\
Detergent (Fairy Liquid) + water (1:4) & 1 & 50 & $25.25 \pm 0.42$ & $102.5 \pm 1.1$ \\
Bleach (Domestos) + water (1:4) & 1 & 50 & $24.81 \pm 0.41$ & $103.5 \pm 1.7$ \\
Water & 3 & 40 & $24.89 \pm 0.30$ & $101.7 \pm 1.7$ \\
Revive Bath Salts in water & 3 & 40 & $24.70 \pm 0.19$ & $102.0 \pm 1.2$ \\
Sols Bath Salts in water & 3 & 40 & $24.69 \pm 0.17$ & $101.2 \pm 0.8$ \\
DeWitt's K\&B Pills in water & 3 & 40 & & $101.2 \pm 0.7$ \\
\hline
\end{tabular}




\subsection{Content/residual content assay}

186 Initial and residual DPV content in the control rings and the rings exposed to the various test 187 solutions, respectively, was assessed by solvent extraction and subsequent HPLC analysis. Upon 188 removal from the test solutions, rings were rinsed with deionised water, blotted dry and weighed. 189 Rings were then sectioned into approximately $2 \mathrm{~mm}$ pieces and reweighed before being placed 190 into individually labelled $250 \mathrm{~mL}$ glass flasks. $5 \mathrm{~mL}$ of NOR internal standard solution (2.5 $191 \mathrm{mg} / \mathrm{mL}$ ) and $95 \mathrm{~mL}$ acetone was added to each flask. Flasks were sealed and placed in a 192 temperature-controlled orbital shaking incubator $\left(37^{\circ} \mathrm{C}, 60 \mathrm{rpm}, 25 \mathrm{~mm}\right.$ orbital throw). After 24 $193 \mathrm{~h}$, the flasks were removed and allowed to cool to ambient temperature for at least $1 \mathrm{~h}$. A $5 \mathrm{~mL}$ 194 aliquot of the acetone extraction solution was transferred to a $25 \mathrm{~mL}$ volumetric flask and diluted 195 with methanol. Flasks were allowed to stand for a further $20 \mathrm{~min}$ at ambient temperature before 196 final dilution to volume with methanol. Samples were transferred to HPLC vials and analysed 197 against standard solutions of known DPV and NOR concentrations.

\subsection{Degradation products assay and impurity identification}

200 For degradation product assay and impurity identification, rings were treated and processed 201 using a similar method as for content assay testing. Rings were extracted using $100 \mathrm{~mL}$ acetone 202 (without internal standard to avoid interference in subsequent chromatography) in a temperature203 controlled $\left(37^{\circ} \mathrm{C}\right)$ orbital shaking incubator. After the flasks were cooled for $\sim 60 \mathrm{~min}$, a $5 \mathrm{~mL}$ 204 aliquot of the extraction solution was transferred to a boiling tube and evaporated to dryness. A 205 1:1 mixture of acetonitrile and water $(5 \mathrm{~mL})$ was added to each boiling tube and the samples 206 reconstituted by agitation on a whirl mixer for 30 s followed by 5 min sonication. Samples were 
207 then centrifuged at $3000 \mathrm{rpm}$ for $2 \mathrm{~min}$ and the resulting solutions filtered through a $0.45 \mu \mathrm{m}$

208 filter before being transferred to HPLC vials for analysis.

209

$210 \quad 2.6$ HPLC methods

211 A Waters HPLC system (Elstree, UK) consisting of; a 1525 binary HPLC pump, a 717 plus

212 autosampler, an in-line degasser unit, a 1500 series column heater, a 2487 dual wavelength

213 absorbance detector and a 2998 photodiode array detector was used for all analysis.

214

215 In vitro release

$21625 \mu \mathrm{L}$ of sample was injected on to a Thermo Scientific BDS Hypersil C18 HPLC column $(150 \mathrm{x}$

$2174.6 \mathrm{~mm}, 3 \mu \mathrm{m}$ particle size) fitted with a guard column. The column was held at $45^{\circ} \mathrm{C}$ and

218 isocratic elution performed using a mobile phase of $45 \%$ acetonitrile and $55 \%$ phosphate buffer

$219(\mathrm{pH} 3.0,7.7 \mathrm{mM})$ with a total flow rate of $1.2 \mathrm{~mL} / \mathrm{min}$ and a run time of $8 \mathrm{~min}$. DPV was

220 detected at $240 \mathrm{~nm}$ after approximately $6.1 \mathrm{~min}$.

221

222 Content assay

$22310 \mu \mathrm{L}$ of sample was injected on to a Kromasil C18 column $(150 \times 4.6 \mathrm{~mm}, 5 \mu \mathrm{m}$ particle size $)$

224 fitted with a guard column. The column was held at $25^{\circ} \mathrm{C}$ and isocratic elution performed using a 225 mobile phase of $75 \%$ methanol and $25 \%$ water. The total flow rate was $0.75 \mathrm{~mL} / \mathrm{min}$ and the run 226 time was $12 \mathrm{~min}$. DPV was detected at $257 \mathrm{~nm}$ after $10.8 \mathrm{~min}$ and NOR was detected at the same 227 wavelength after $5.3 \mathrm{~min}$.

228

229

Degradation products assay 
$23050 \mu \mathrm{L}$ of sample was injected on to a Kromasil C18 column $(250 \times 4.6 \mathrm{~mm}, 5 \mu \mathrm{m}$ particle size $)$

231 fitted with a guard column. The column was held at $25^{\circ} \mathrm{C}$ and gradient elution performed using a

232 mobile phase of $0.1 \% \mathrm{v} / \mathrm{v}$ TFA in water and $0.1 \% \mathrm{v} / \mathrm{v}$ TFA in acetonitrile mixed according to the

233 schedule in Table 4. The total flow rate was $1.0 \mathrm{~mL} / \mathrm{min}$ and the run time was $51 \mathrm{~min}$. DPV was

234 detected at $245 \mathrm{~nm}$ after $21 \mathrm{~min}$. A resolution solution containing a DPV isomer and a closely

235 related structural analogue were also run to ensure adequate separation.

236

237 Table 4. Mobile phase composition for the gradient elution of DPV in the degradation products analysis.

\begin{tabular}{lll}
\hline $\begin{array}{l}\text { Time } \\
(\mathrm{min})\end{array}$ & $\begin{array}{l}\text { \% mobile phase A } \\
(0.1 \% \text { TFA in water })\end{array}$ & $\begin{array}{l}\text { \% mobile phase B } \\
(0.1 \% \text { TFA in acetonitrile })\end{array}$ \\
\hline 0.0 & 70 & 30 \\
40.0 & 30 & 70 \\
40.5 & 5 & 95 \\
45.5 & 5 & 95 \\
46.0 & 70 & 30 \\
51.0 & 70 & 30 \\
\hline
\end{tabular}

238

239

\subsection{Analysis}

241 In vitro release concentrations obtained via HPLC were used to calculate total daily amount of

242 DPV released and cumulative release amount. Residual content values were calculated for each

243 ring and compared to the mean content assay value determined for this batch of rings. To

244 determine when differences between groups were statistically significant, mean values were

245 compared using a one-way analysis of variance. Where appropriate, post hoc comparisons were

246 conducted using Tukey-Kramer multiple comparisons test with a 95\% significance level. In the

247 degradation products assay, injections of blank extraction solutions and mobile phase were

248 examined for baseline quality. Chromatograms from replicate samples were overlaid to ensure

249 consistency of peak appearance. A relative retention time (RRT) window of \pm 0.02 either side of 
250 an unknown peak eluting before DPV was used as the basis for assigning a similar peak label to

251 a subsequent chromatogram. For peaks eluting after DPV, an RRT window of \pm 0.04 was used.

252 Degradation products providing peak areas greater than $0.1 \% \mathrm{w} / \mathrm{w}$ were recorded and

253 investigated further. Degradation products at peak areas representing between 0.02 and $0.1 \%$

$254 \mathrm{w} / \mathrm{w}$ were noted but not investigated further. Integrated peaks which gave degradation values less

255 than $0.02 \% \mathrm{w} / \mathrm{w}$ were not considered further.

\section{3. Results and Discussion}

\subsection{In vitro release testing of rings on intermittent use}

259 In vitro release versus time profiles for $25 \mathrm{mg}$ DPV rings placed on either continuous or

260 intermittent release over 28 days are presented in Figure 1. DPV release into IPA/water (P1-P6,

261 Table 2) are presented in plots A, B and C, and release into SVF/Tween (S1-S6, Table 2) in

262 plots D, E and F. Data for 28-day continuous release of DPV from the ring into IPA/water (group

263 PC) or SVF/Tween (group SC) is also presented in each plot for reference. Plots A and D display

264 daily DPV release from rings tested on Day 1 and Day 28 for IPA/water (group P1 and P2, Table

265 2) and SVF/Tween (group S1 \& S2, Table 2), respectively. Plots B and E show daily release

266 from rings tested on days 1, 7, 14, 21 and 28 into IPA/water (groups P3 and P4, Table 2) and

267 SVF/Tween (groups S3 and S4, Table 2), respectively. Plots C and F display daily release from

268 rings tested on days 1-7 and 21-28 into IPA/water (groups P5 and P6, Table 2) and SVF/Tween

269 (groups S5 and S6, Table 2), respectively. The dashed arrows in each figure correlate the daily

270 release values obtained under the different intermittent release testing schedules with the

271 equivalent daily release values for rings tested under the continuous 28 -day release schedule.

272 Where the gradient of the arrow is zero or close to zero, there is no substantial difference 
273 between the daily release value measured upon testing after storage and an equivalent release

274 value measured from rings which were not on storage. It can therefore be concluded that the

275 majority of rings showed no appreciable difference in the amounts of DPV released from rings

276 used intermittently and those used continuously when daily release values were compared based

277 only on the number of days - and not necessarily consecutive days - spent on release (Figure 1A,

278 B, C, D and F). S3 and S4 rings displayed a small, but not statistically significant, difference

279 between the amounts of DPV released for rings with and without interruption of release testing

280 into SVF/Tween (Figure 1E). The daily release values for these rings tested after storage was

281 slightly higher than for rings tested under the continuous regimen (hence the dashed arrow has a

282 negative gradient, Figure 1E). The mean residual content and mean cumulative release values

283 measured for each ring are presented in Table 2, demonstrating complete DPV recovery when

284 cumulative release and residual content values are summated, and indicating that no loss of drug

285 to other surfaces had occurred during the period of ring removal. Ring storage temperature (room

286 temperature $v s .4^{\circ} \mathrm{C}$ ) did not have any substantial impact on the daily release values for any of

287 the rings tested.

288

289 The observation that stored rings pick up the expected in vitro drug release rate after return to the

290 release medium is interesting. No leaching or loss of drug from the system is possible during

291 storage, as there is no surrounding medium for dissolved drug to partition into. Without release

292 of dissolved drug from the polymer matrix, the remaining solid drug will be unable to dissolve as

293 the system is already saturated. Of course, this observation would likely not hold if the rings

294 were to be stored in a liquid medium following removal from the body. In the event that a ring is

295 removed during use - either by choice or expulsion - the concentrations of DPV already present 
296 in the biological compartments would be expected to decline according to the terminal

297 elimination half-life of DPV in that compartment e.g. 12-14 $\mathrm{h}$ in vaginal fluid and $67 \mathrm{~h}$ in

298 plasma (Nel et al., 2014).

299

300

3.2 Ring exposure to bath salts, detergent, bleach and personal lubricating

agents

302 To assess the impact of exposure to bath salts, liquid detergent, bleach or personal lubricants

303 upon the $25 \mathrm{mg}$ ring, rings were exposed under controlled conditions to test solutions and the

304 DPV content quantified following solvent extraction. Extraction solutions were also assessed for

305 DPV degradation products. The mean residual DPV content values for each ring group following

306 exposure to the various test solutions are presented in Table 3. The lowest amount of DPV

307 measured per ring was $24.17 \mathrm{mg}$, equivalent to $99.1 \%$ of theoretical based on a measured mean

308 value of $24.4 \mathrm{mg} \mathrm{DPV}$ per ring for this batch. These data indicate that no significant reduction in

309 DPV content was observed following exposure to the any of the personal lubricants or wash

310 solutions tested in this study. Of note, a pink discolouration was visible on the surface of all rings

311 exposed to the Sols bath salt solution (Figure 2A), which rinsing with deionised water did not

312 remove. On sectioning the rings, the discolouration was determined to be largely a surface effect,

313 although given the limited exposure time, substantial migration through the ring would seem

314 unlikely (Figure 2B). The discolouration had no impact on the amount of DPV recovered from

315 this ring (Table 3). The discolouration observed in this study is consistent with ring

316 discolouration previously observed in some used silicone elastomer rings returned from clinical

317 sites (IPM, unpublished results). 
319 To determine whether exposure of the ring to any of the wash solutions had the potential to cause

320 DPV degradation, a further set of rings were treated and extracted - this time without addition of

321 an internal standard - and the extraction solutions tested for the presence of significant

322 breakdown products. The results are summarised in Table 5. Rings exposed to personal lubricant

323 solutions were not examined due to concerns about injecting certain formulation components

324 onto the HPLC system.

325

326 Exposure of the DPV ring to different bath salts, a pill, and various cleaning solutions (Table 1)

327 produced up to three additional, low-level peaks in the degradation products analysis relative to

328 the control rings (Table 5). However, in all cases, a similar mean sum of degradation products

$329(0.3-0.4 \% \mathrm{w} / \mathrm{w})$ was observed for untreated control rings. Exposure to detergent or bleach

330 solutions produced no new unknown peaks greater than $0.1 \% \mathrm{w} / \mathrm{w}$. Untreated rings also

331 produced unknown peaks $>0.1 \% \mathrm{w} / \mathrm{w}$ at the same relative retention time as those observed with

332 the detergent and bleach treatments. This suggests that exposure to the products tested in this

333 study did not significantly impact the impurity profile of the $25 \mathrm{mg}$ DPV ring. 
Table 5. Degradation products observed after treatment of the $25 \mathrm{mg}$ DPV ring with bath salts, bleach and detergent solutions. $\mathrm{n}=3$ rings per study group. Unk - unknown peaks

\begin{tabular}{lllll}
\hline Treatment solution & $\begin{array}{l}\text { Average sum of } \\
\text { degradation } \\
\text { products (\%) }\end{array}$ & $\begin{array}{l}\text { Number of } \\
\text { unknowns }\end{array}$ & $\begin{array}{l}\text { Unknowns } \\
>0.1 \% \mathrm{w} / \mathrm{w}\end{array}$ & Remarks \\
\hline Untreated & 0.4 & 4 & Unk 1 \& 2 & - \\
$\begin{array}{l}\text { Detergent (Fairy Liquid) } \\
+ \text { water (1:4) }\end{array}$ & 0.4 & 6 & Unk 1 \& 2 & $\begin{array}{l}\text { Unk 1 \& 2 present in } \\
\text { untreated ring extracts }\end{array}$ \\
$\begin{array}{l}\text { Bleach (Domestos) }+ \\
\text { water (1:4) }\end{array}$ & 0.4 & 3 & Unk 1 \& 2 & $\begin{array}{l}\text { Unk 1 \& 2 present in } \\
\text { untreated ring extracts }\end{array}$ \\
$\begin{array}{l}\text { Water } \\
\begin{array}{l}\text { Revive Bath Salts in } \\
\text { water }\end{array}\end{array}$ & 0.3 & 5 & 0 & - \\
$\begin{array}{l}\text { Sols Bath Salts in water } \\
\text { DeWitt's K\&B Pills in }\end{array}$ & 0.4 & 6 & 0 & - \\
water & 0.3 & 7 & 0 & - \\
\hline
\end{tabular}

\section{4. Conclusions}

338 In vitro release testing of the $25 \mathrm{mg}$ DPV matrix-type silicone vaginal ring under various

339 intermittent use schedules produced no substantial impact on the rate of DPV release when

340 compared to rings released continuously for 28 days. Ring storage conditions (ambient

341 temperature or $4^{\circ} \mathrm{C}$ ) had no impact on DPV release rates in vitro. Exposure of rings to a range of

342 aqueous solutions derived from bath salts, an oral pill, bleach, detergent and personal lubricants

343 had no significant impact on the amount of DPV present. No new degradation products $(\geq 0.1 \%$

$344 \mathrm{w} / \mathrm{w}$ ) were observed following exposure to detergent, bleach, pill or bath salt treatments. These

345 results indicate that drug release from the $25 \mathrm{mg}$ DPV ring is unaffected by periodic removal and

346 reinsertion of the ring. In addition, the ring is tolerant of exposure to a range of wash or personal

347 lubricant solutions, in terms of both drug content and stability. 
351 *R. Karl Malcolm, School of Pharmacy, Medical Biology Centre, Queen's University Belfast, 352 Belfast BT9 7BL, United Kingdom. Tel: +44 (0)28 9097 2319. Email: k.malcolm@qub.ac.uk

\section{Author Contributions}

355 All authors contributed to the design of experiments and analysis of data. D.J.M and C.F.M

356 conducted the experimental work. The manuscript was drafted by D.J.M, C.F.M and R.K.M with

357 input from other authors. All authors approved submission of the manuscript.

\section{Declaration of Interest}

360 The authors declare no competing financial or personal interest.

\section{Acknowledgements}

363 This work was funded by the International Partnership for Microbicides, which receives 364 generous support from the Danish Ministry of Foreign Affairs, Flanders Department of Foreign 365 Affairs, Irish Aid, the German Federal Ministry of Education and Research (BMBF) through the 366 KfW Development Bank, the Ministry of Foreign Affairs of the Netherlands, UK aid from the 367 British people, the American people through the United States Agency for International 368 Development (USAID) in partnership with the US President's Emergency Plan for AIDS Relief 369 (PEPFAR), and the Bill \& Melinda Gates Foundation. 


\section{Figure Legends}

371

372 Fig. 1. In vitro daily release versus time profiles for rings releasing into IPA/water (group P rings, plots

373 A, B and C) and SVF/Tween (group S rings, plots D, E and F). Data for control rings PC and SC,

374 representing continuous release over 28 days into IPA/water or SVF/Tween respectively, are presented in 375 each panel for reference. P1, P2 \& S1, S2 represent rings released on days 1 and 28 only. P3, P4, S3 and 376 S4 represent rings released on days 1, 7, 14, 21 and 28. Groups P5, P6, S5 and S6 represent rings released

377 on days 1-7 and 21-28. Rings from groups 1, 3 and 5 were stored at room temperature when not on

378 release, and rings from groups 2,4 and 6 at $4^{\circ} \mathrm{C}$. Dashed lines are intended to invite comparisons between

379 daily release values measured after a period of storage with the equivalent timepoint for rings that

380 underwent continuous release testing, e.g. for rings that were released on days 1 and 28 only, the day 28

381 value is compared with the day 2 value from the continuous release test.

382

383 Fig. 2. Discolouration observed upon treatment of $25 \mathrm{mg}$ DPV matrix-type rings with Sols bath salts

384 solution; (A) full ring, (B) ring segments. 


\section{References}

386

Baeten, J., Palanee-Phillips, T., Mgodi, N., Mayo, A., Nel, A., Rosenberg, Z., Hillier, S.L., Brown, E., 2018. Baeten J CROI 2018. Top. Antivir. Med. 26, 483.

Baeten, J.M., Palanee-Phillips, T., Brown, E.R., Schwartz, K., Soto-Torres, L.E., Govender, V., Mgodi, N.M., Matovu Kiweewa, F., Nair, G., Mhlanga, F., Siva, S., Bekker, L.-G., Jeenarain, N., Gaffoor, Z., Martinson, F., Makanani, B., Pather, A., Naidoo, L., Husnik, M., Richardson, B.A., Parikh, U.M., Mellors, J.W., Marzinke, M.A., Hendrix, C.W., van der Straten, A., Ramjee, G., Chirenje, Z.M., Nakabiito, C., Taha, T.E., Jones, J., Mayo, A., Scheckter, R., Berthiaume, J., Livant, E., Jacobson, C., Ndase, P., White, R., Patterson, K., Germuga, D., Galaska, B., Bunge, K., Singh, D., Szydlo, D.W., Montgomery, E.T., Mensch, B.S., Torjesen, K., Grossman, C.I., Chakhtoura, N., Nel, A., Rosenberg, Z., McGowan, I., Hillier, S., 2016. Use of a Vaginal Ring Containing Dapivirine for HIV-1 Prevention in Women. N. Engl. J. Med. 375, 2121-2132.

https://doi.org/10.1056/NEJMoa1506110

Boyd, P., Fetherston, S.M., McCoy, C.F., Major, I., Murphy, D.J., Kumar, S., Holt, J., Brimer, A., Blanda, W., Devlin, B., Malcolm, R.K., 2016. Matrix and reservoir-type multipurpose vaginal rings for controlled release of dapivirine and levonorgestrel. Int. J. Pharm. 511, 619-629. https://doi.org/10.1016/j.ijpharm.2016.07.051

Clark, J.T., Clark, M.R., Shelke, N.B., Johnson, T.J., Smith, E.M., Andreasen, A.K., Nebeker, J.S., Fabian, J., Friend, D.R., Kiser, P.F., 2014. Engineering a segmented dual-reservoir polyurethane intravaginal ring for simultaneous prevention of HIV transmission and unwanted pregnancy. PLoS One 9, e88509. https://doi.org/10.1371/journal.pone.0088509

Cocks, M., Moller, V., 2002. Use of indigenous and indigenised medicines to enhance personal wellbeing: A South African case study. Soc. Sci. Med. https://doi.org/10.1016/S0277-9536(01)00037-5 Dai, J.Y., Hendrix, C.W., Richardson, B.A., Kelly, C., Marzinke, M., Chirenje, Z.M., Marrazzo, J.M., Brown, E.R., 2016. Pharmacological measures of treatment adherence and risk of HIV infection in 
the VOICE study. J. Infect. Dis. 213, 335-342. https://doi.org/10.1093/infdis/jiv333

Dieben, T.O.M., Roumen, F.J.M.E., Apter, D., 2002. Efficacy, cycle control, and user acceptability of a novel combined contraceptive vaginal ring. Obstet. Gynecol. 100, 585-93.

413

414

415

416

417

418

419

420

421

422

423

424

425

426

427

428

429

430

431

432

433

434

435

Gafos, M., Mzimela, M., Sukazi, S., Pool, R., Montgomery, C., Elford, J., 2010. Intravaginal insertion in KwaZulu-Natal: Sexual practices and preferences in the context of microbicide gel use. Cult. Heal. Sex. 12, 929-942. https://doi.org/10.1080/13691058.2010.507876

Kashuba, A.D.M., Gengiah, T.N., Werner, L., Yang, K., White, N.R., Karim, Q.A., Abdool Karim, S.S., 2015. Genital Tenofovir Concentrations Correlate With Protection Against HIV Infection in the CAPRISA 004 Trial: Importance of Adherence for Microbicide Effectiveness. J. Acquir. Immune Defic. Syndr. 69, 264-9. https://doi.org/10.1097/QAI.0000000000000607

Low, N., Chersich, M.F., Schmidlin, K., Egger, M., Francis, S.C., van de Wijgert, J.H.H.M., Hayes, R.J., Baeten, J.M., Brown, J., Delany-Moretlwe, S., Kaul, R., McGrath, N., Morrison, C., Myer, L., Temmerman, M., van der Straten, A., Watson-Jones, D., Zwahlen, M., Hilber, A.M., 2011. Intravaginal practices, bacterial vaginosis, and HIV infection in women: individual participant data meta-analysis. PLoS Med. 8, e1000416. https://doi.org/10.1371/journal.pmed.1000416

MacQueen, K.M., Tolley, E.E., Owen, D.H., Amico, K.R., Morrow, K.M., Moench, T., Friend, D.R., Friedland, B., 2014. An interdisciplinary framework for measuring and supporting adherence in HIV prevention trials of ARV-based vaginal rings. J. Int. AIDS Soc. 17, 1-7. https://doi.org/10.7448/IAS.17.3.19158

Malcolm, R.K., Boyd, P., McCoy, C.F., Murphy, D.J., 2014. Beyond HIV microbicides: Multipurpose prevention technology products. BJOG An Int. J. Obstet. Gynaecol. 121, 62-69. https://doi.org/10.1111/1471-0528.12852

Malcolm, R.K., Boyd, P.J., McCoy, C.F., Murphy, D.J., 2016. Microbicide vaginal rings: Technological challenges and clinical development. Adv. Drug Deliv. Rev. 103, 33-56. https://doi.org/10.1016/j.addr.2016.01.015

Marrazzo, J.M., Ramjee, G., Richardson, B.A., Gomez, K., Mgodi, N., Nair, G., Palanee, T., Nakabiito, 
C., van der Straten, A., Noguchi, L., Hendrix, C.W., Dai, J.Y., Ganesh, S., Mkhize, B., Taljaard, M., Parikh, U.M., Piper, J., Mâsse, B., Grossman, C., Rooney, J., Schwartz, J.L., Watts, H., Marzinke,

Martin Hilber, A., Hull, T.H., Preston-Whyte, E., Bagnol, B., Smit, J., Wacharasin, C., Widyantoro, N., 2010. A cross cultural study of vaginal practices and sexuality: Implications for sexual health. Soc.

Montgomery, E.T., Van Der Straten, A., Cheng, H., Wegner, L., Masenga, G., Von Mollendorf, C., Sci. Med. 70, 392-400. https://doi.org/10.1016/j.socscimed.2009.10.023

McKinnon, L.R., Liebenberg, L.J., Yende-Zuma, N., Archary, D., Ngcapu, S., Sivro, A., Nagelkerke, N., Lerma, J.G.G., Kashuba, A.D., Masson, L., Mansoor, L.E., Karim, Q.A., Karim, S.S.A., Passmore, J.A.S., 2018. Genital inflammation undermines the effectiveness of tenofovir gel in preventing HIV acquisition in women. Nat. Med. 24, 491-496. https://doi.org/10.1038/nm.4506 Bekker, L., Ganesh, S., Young, K., Romano, J., Nel, A., Woodsong, C., 2012. Vaginal ring adherence in sub-saharan Africa: Expulsion, removal, and perfect use. AIDS Behav. 16, 1787-1798. https://doi.org/10.1007/s10461-012-0248-4

Montgomery, E.T., Van Der Straten, A., Chitukuta, M., Reddy, K., Woeber, K., Atujuna, M., Bekker, L.G., Etima, J., Nakyanzi, T., Mayo, A.J., Katz, A., Laborde, N., Grossman, C.I., Soto-Torres, L., Palanee-Phillips, T., Baeten, J.M., 2017. Acceptability and use of a dapivirine vaginal ring in a phase III trial. Aids 31, 1159-1167. https://doi.org/10.1097/QAD.0000000000001452

Nel, A., Bekker, L.-G., Bukusi, E., Hellström, E., Kotze, P., Louw, C., Martinson, F., Masenga, G., Montgomery, E., Ndaba, N., van der Straten, A., van Niekerk, N., Woodsong, C., 2016a. Safety, Acceptability and Adherence of Dapivirine Vaginal Ring in a Microbicide Clinical Trial Conducted in Multiple Countries in Sub-Saharan Africa. PLoS One 11, e0147743. https://doi.org/10.1371/journal.pone.0147743

Nel, A., Haazen, W., Nuttall, J., Romano, J., Rosenberg, Z., Van Niekerk, N., 2014. A safety and 
pharmacokinetic trial assessing delivery of dapivirine from a vaginal ring in healthy women. Aids 28, 1479-1487. https://doi.org/10.1097/QAD.0000000000000280

Nel, A., van Niekerk, N., Kapiga, S., Bekker, L.-G., Gama, C., Gill, K., Kamali, A., Kotze, P., Louw, C.,

Nel, A., van Niekerk, N., Van Baelen, B., Rosenberg, Z., 2018. Nel A CROI 2018. Top. Antivir. Med. 26, 483.

Novák, a., De La Loge, C., Abetz, L., Van Der Meulen, E. a., 2003. The combined contraceptive vaginal

Owen, D.H., Katz, D.F., 1999. A vaginal fluid simulant. Contraception 59, 91-95. https://doi.org/10.1016/S0010-7824(99)00010-4

Pines, H.A., Semple, S.J., Strathdee, S.A., Hendrix, C.W., Harvey-Vera, A., Gorbach, P.M., MagisRodríguez, C., Martinez, G., Patterson, T.L., 2018. Vaginal washing and lubrication among female sex workers in the Mexico-US border region: implications for the development of vaginal PrEP for HIV prevention. BMC Public Health 18, 1009. https://doi.org/10.1186/s12889-018-5946-z rings containing antiviral agents for HIV prevention. Curr. Opin. HIV AIDS 10, 264-70. https://doi.org/10.1097/COH.0000000000000157

Spence, P., Nel, A., van Niekerk, N., Derrick, T., Woodsong, C., Wider, S., Devlin, B., 2016. Objective 
instructions for using the Nestorone ${ }^{\circledR} /$ ethinyl estradiol contraceptive vaginal ring. Contraception 97 , 415-421. https://doi.org/10.1016/j.contraception.2017.12.011

Thurman, A.R., Clark, M.R., Hurlburt, J.A., Doncel, G.F., 2013. Intravaginal rings as delivery systems for microbicides and multipurpose prevention technologies. Int. J. Womens. Health 5, 695-708. https://doi.org/10.2147/IJWH.S34030

Van Damme, L., Corneli, A., Ahmed, K., Agot, K., Lombaard, J., Kapiga, S., Malahleha, M., Owino, F., Manongi, R., Onyango, J., Temu, L., Monedi, M.C., Mak'Oketch, P., Makanda, M., Reblin, I., Makatu, S.E., Saylor, L., Kiernan, H., Kirkendale, S., Wong, C., Grant, R., Kashuba, A., Nanda, K.,

Van Der Straten, A., Montgomery, E.T., Cheng, H., Wegner, L., Masenga, G., Von Mollendorf, C., Bekker, L., Ganesh, S., Young, K., Romano, J., Nel, A., Woodsong, C., 2012. High acceptability of a vaginal ring intended as a microbicide delivery method for HIV prevention in African women. AIDS Behav. 16, 1775-1786. https://doi.org/10.1007/s10461-012-0215-0 Fumarate Vaginal Ring for HIV Prevention Among Women in New York City. AIDS Behav. 22, 421-436. https://doi.org/10.1007/s10461-017-1962-8

Woodsong, C., Holt, J.D.S., 2015. Acceptability and preferences for vaginal dosage forms intended for prevention of HIV or HIV and pregnancy. Adv. Drug Deliv. Rev. 92, 146-154. https://doi.org/10.1016/j.addr.2015.02.004 


\section{Declaration of Interest}

The authors declare no competing financial or personal interest. 
A

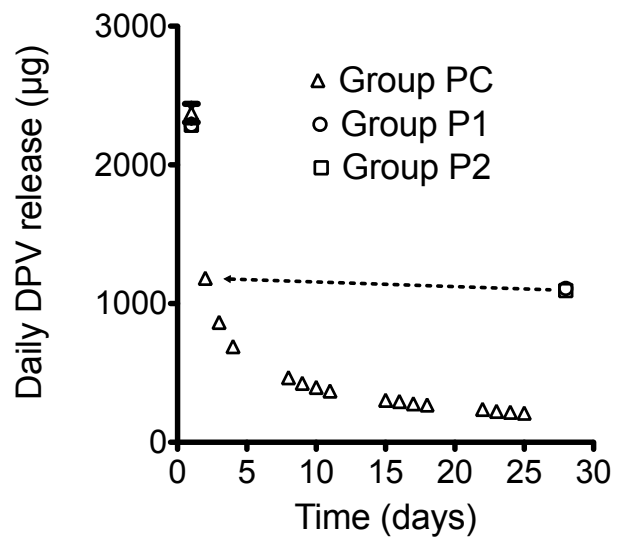

D

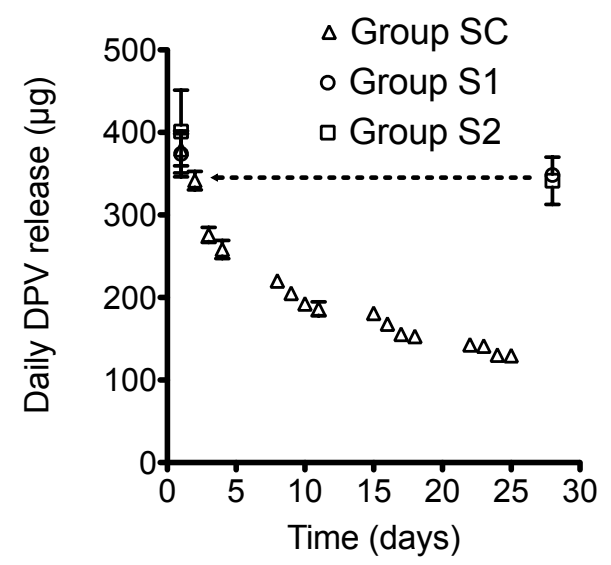

B

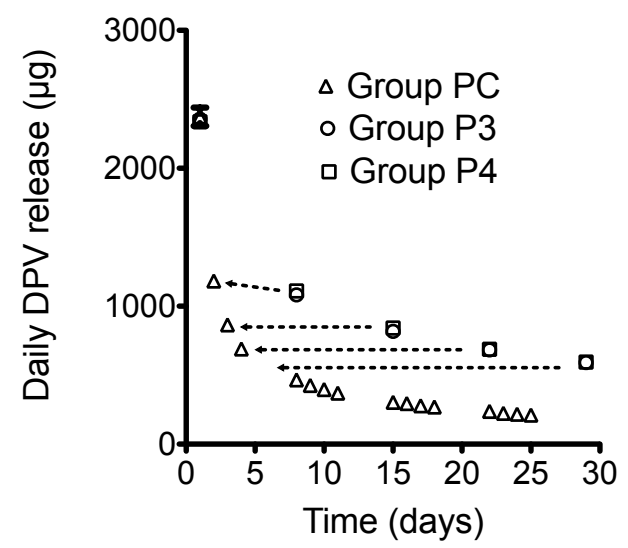

E

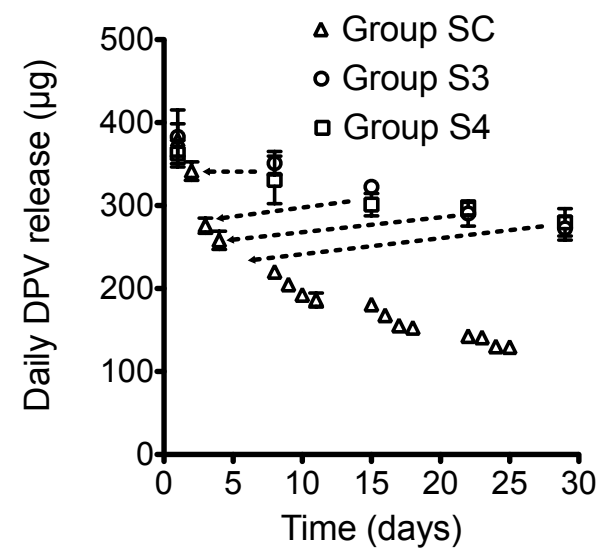

C

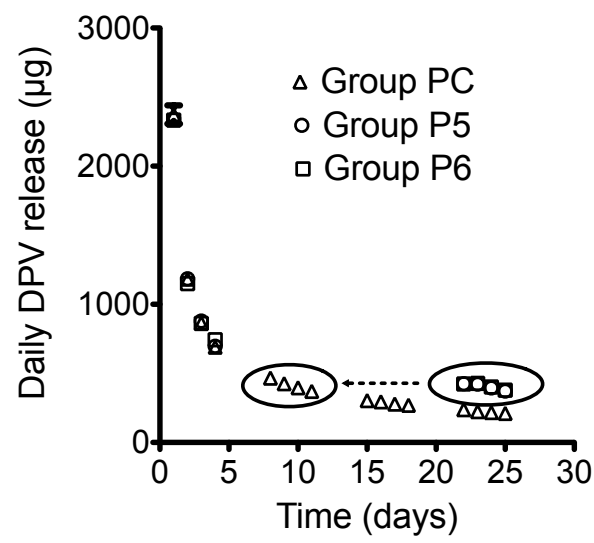

F

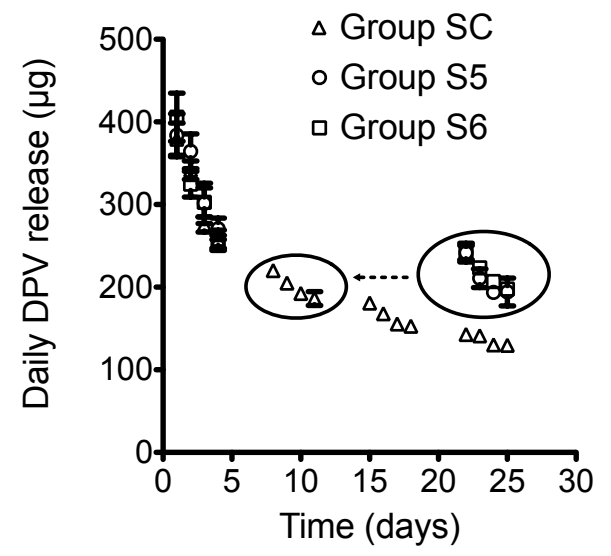


A

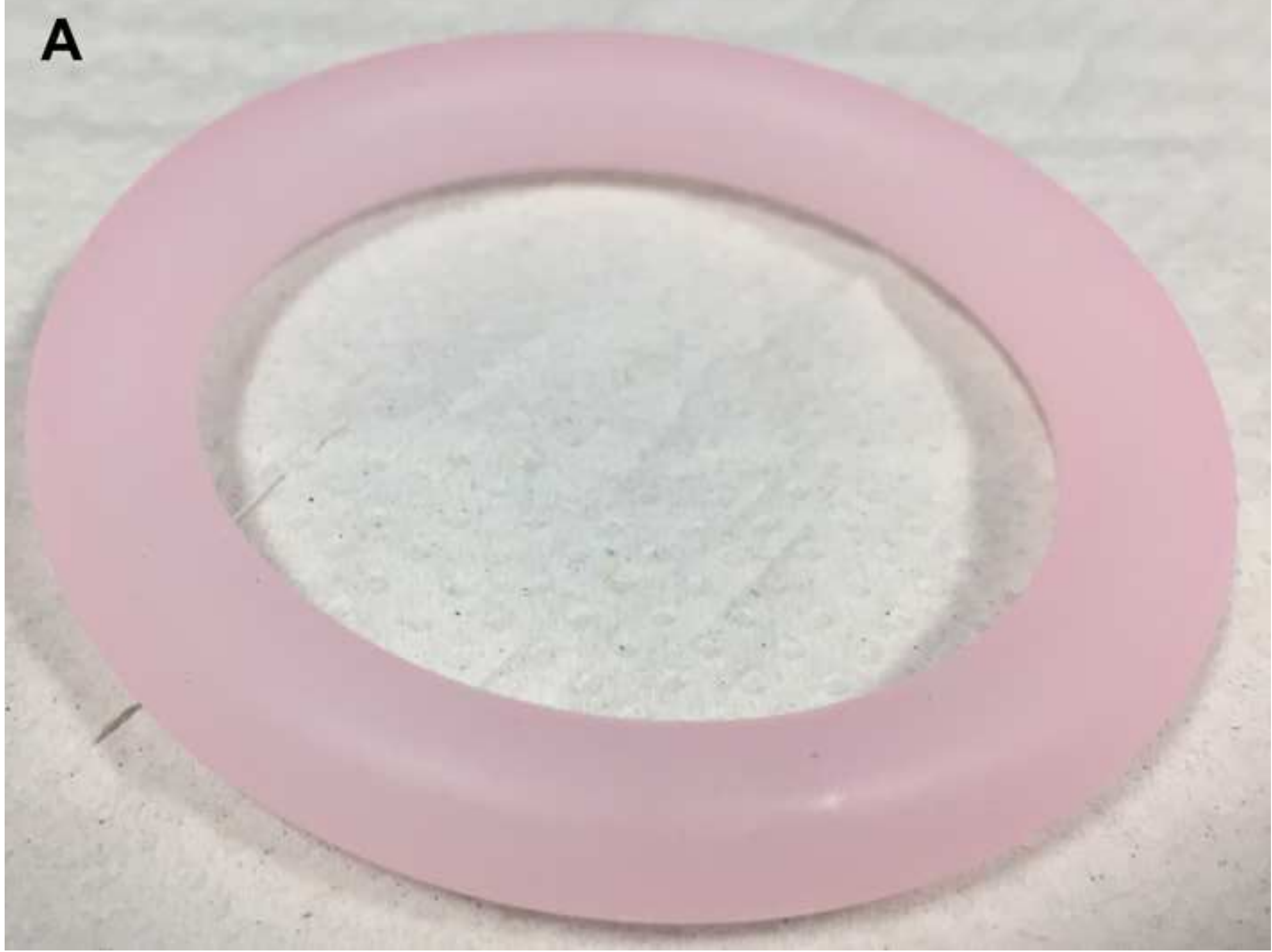


B

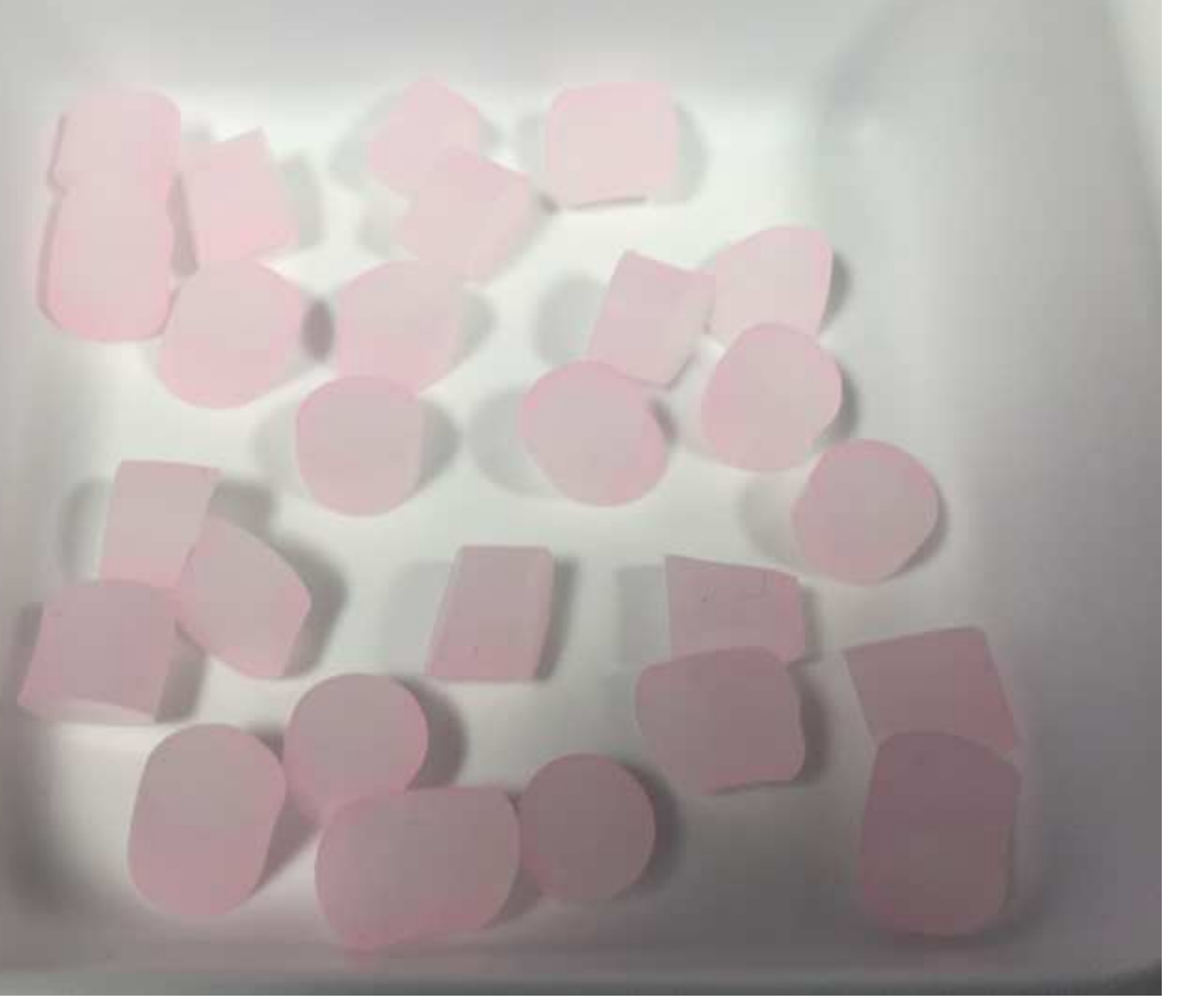

B
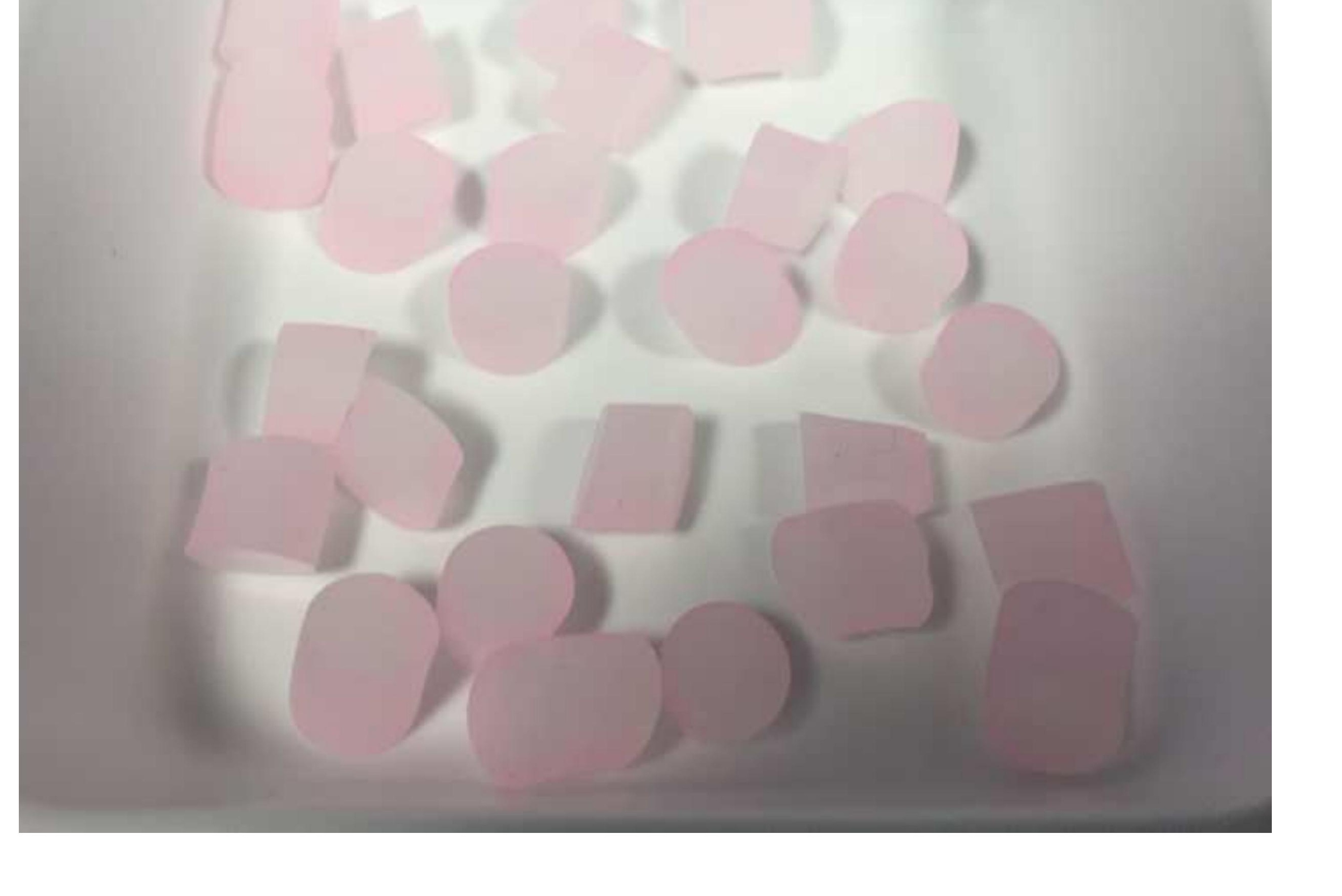

3 